\title{
Presenting an environmental performance evaluation model for gas refineries: A case study in the South Pars Gas Complex, Iran
}

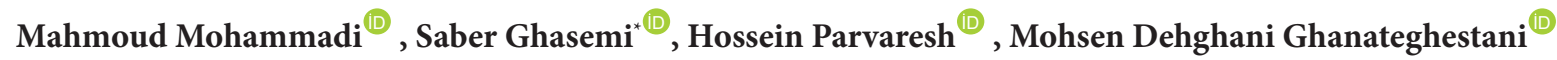 \\ Department of Environment, Faculty of Natural Resources, Islamic Azad University, Bandar Abbas Branch, Bandar Abbas, Iran
}

\begin{abstract}
Background: Controlling and validating the environmental performance of organizations, is a major problem that has been stated in the international standard ISO 14031. The aim of this study was to present a model for evaluating the environmental performance of Iran's gas refineries using the environmental performance evaluation (EPE) method, based on the operational performance index (OPI) and management performance index (MPI). This case study was conducted in the ninth refinery of the South Pars Gas Complex (SPGC), Bushehr province, Iran, during 2019-2020.

Methods: The research method comprises two stages. The first stage was distinguishing the standards and markers of the MPI and OPI using the Fluffy Delphi strategy and the second one was focusing on and relegating loads to the measures and pointers using the logical analytical hierarchy process (AHP) prior to confirming the outcomes by applying the TOPSIS.

Results: The total normal scores of the total OPIt and OPTt were obtained to be 2.3409 and 2.2647, respectively. Considering these coefficients, the organization is balanced in terms of the environmental performance. The implementation steps of the TOPSIS method in the ninth refinery $\left(A_{1}\right)$ with the first $\left(A_{2}\right)$, second $\left(A_{3}\right)$, and third $\left(A_{4}\right)$ refineries, which had the same extraction indices of OPIt and MPIt, were ranked as $A_{1}>A_{3}>A_{4}>A_{2}$, respectively.

Conclusion: Petrochemical industries have the potential to cause adverse effects on the environment due to the nature of activities and effluents production, emissions, and hazardous wastes. However, they can increase their weight to be more competitive and reach the ranks of mature organizations by planning on important indices.

Keywords: Functional performance, Environmental indicators, South Pars Gas Complex, Iran

Citation: Mohammadi M, Ghasemi S, Parvaresh H, Dehghani Ghanateghestani M. Presenting an environmental performance evaluation model for gas refineries: A case study in the South Pars Gas Complex, Iran. Environmental Health Engineering and Management Journal 2021; 8(2): 95-106. doi: 10.34172/EHEM.2021.13.
\end{abstract}

\section{Introduction}

Increasing of population growth, industrialization, shortage, and in some cases, the destruction of natural resources $(1,2)$, have made human beings to think about and reflect on the type and manner of their interaction with the environment $(3,4)$. In order to have a proper management system, measurement tools should be created (5). Therefore, many organizations are looking for ways to understand, detect, and improve their environmental performance (6).

With the aim of controlling and validating the environmental performance of organizations, environmental knowledge has developed various types of environmental performance assessment (7).

Environmental performance evaluation (EPE) as stated in the international standard ISO 14031, is a management process that enables the organization to measure and evaluate its performance in the field of environment using key performance indicators (KPIs) and provide reliable and verifiable information to stakeholders (8). However, a little known standard is provided by ISO 14031 compared to ISO 14001; in addition, it includes an outline of conducting environmental indicators of the EPD and their function (9).

Environmental product declaration shows how effective we are performing according to our ecological objectives (10), for instance, if we plan to achieve an objective to decrease consuming energy in the workplace, as a result, we could adjust the indicators for environmental performance which covers the required amount of electricity used in the office per month. So, the purpose of performance evaluation is to provide a model for defining specific indicators, measuring periodicity of indicators, as well as reporting environmental performance to the community and stakeholders with a common statement (11). 
Measurements are used to monitor the performance and indicators which are taken into account to give the summery or simplification of applicable information about the complexity of the system (12). Many industries are looking for ways to better identify, understand, recognize, and improve their environmental performance presentation (13), which can be achieved if environmental factors are managed efficiently and effectively (14). Industries optimally manage these activities, products and services that have significant impacts on the environment (15). Every organization in order to present its environmental performance needs a necessary leverage to better introduce the efforts made to comply with environmental standards (16).

Environmental performance indicators that are directly related to business are divided into two categories (10);

1. Management performance indices (MPIs), which measure how well an organization's environmental impacts are being managed.

2. Operational performance indices (OPIs), that specifically cover the environmental performance of operations.

In order to determine how an organization performs in complying with the established standards and legal requirements, an internal management process, which is a tool for providing information and determining a credible and verifiable status for management, is needed (17). For this purpose, the management tools of Delphi, SWOT, TOPSIS, LCA, etc can be used (18-20).

The main challenge faced by many researchers is an EPE model for gas refineries. Previous research showed that the manager can order risk reduction decision makings (21). The findings of fuzzy cognitive maps can be used to determine the causal structure of health, safety and environment (HSE) factors and system performance indicators (22). In addition, according to macroergonomics factors provided by Asadzadeh et al (23), instructions and education, familiarity with organizations' rules, and proper communications help to improve safety, satisfaction, and productivity. To present a multicriteria model for evaluating environmental performance, Guijarro (24), also has presented a purposeful model of programming, in which countries are ranked according to multi-component nature of ecological performance criteria with 24 performance indicators and 10 subject classification.

South Pars gas filed located in Iran is the adjunct of Qatar's enormous North field, an area of 9700 square kilometers covered by the huge offshore field, 3700 of which are Iran's inland waters in the Persian Gulf. North Dome which is the name of the remaining 6000 square kilometers, is located in Qatar's inland waters.

The field's condensate production, depending on the natural gas output, is about 600000 barrels per day, which is mainly transported to the persian gulf star refinery (PGSR) as feedstock, while the refinery supplies $40 \%$ of the country's gasoline. The field's condensate construction, depending on the flammable gas yield, is around 600000 barrels each day, which is predominantly moved to the PGSR as feedstock, while the processing plant supplies $40 \%$ of the nation's fuel. The field is assessed to contain a lot of flammable gas, representing around $8 \%$ of the world's stores (48\% of the all-out gas of Iran), and approximately, 18 billion barrels of condensate. In addition, during the 20 years of South Pars development, $\$ 80$ billion has been put resources into this field (25). This volume of energy source, while creating wealth for a country, can be a source of pollution and environmental degradation. For this reason, in order to produce sustainable and green gas refineries, it is necessary to evaluate the environmental performance of the EPE. The purpose of this study was to present a model for evaluating the environmental performance of the ninth refinery of the South Pars Gas Complex (SPGC), Bushehr province, Iran during 2019-2020 using the EPE method. This model was applied based on the OPI and MPI.

\section{Materials and Methods \\ Scope of study}

The present study aimed to provide a model for evaluating the environmental performance of gas refineries as a case study basis in the ninth refinery (phase 12) of the SPGC. Well-known as a top pioneering company in Iran's projects, the ninth refinery has been a role model for other Iranian companies in previous years and has been responsible for mega and difficult national projects. In this research, the MPIs and OPIs of this refinery have been compared with similar refineries including the first refinery (phase 1), the second refinery (phases 2 and 3), and the third refinery (phases 4 and 5) trough out the extraction of OPIt and MPIt.

It is noteworthy that the SPGC was set up in 1998, in order to work seminal periods of the South Pars Gas Field, as an auxiliary organization of the National Iranian Gas Company (NIGC). Currently, it works in ten stages in five processing plants. In addition, the National Iranian Oil Company (NIOC) has planned to extend the field in 24 or 30 stages with the capacity of creating around 25 billion cubic feet ( 710 million cubic meters) to 30 billion cubic feet (850 million cubic meters) of petroleum gas every day. Each standard stage should create about 1 billion cubic feet (28 million cubic meters) of flammable gas, 40000 barrels (6400 cubic meters) of condensate, 1500 tons of liquefied petroleum gases, and 200 tons of sulfur, however, a few stages have been characterized to do diverse tasks. The assessed normal capital spends for each of the stages is around US\$1.5 billion (26).

\section{Methods}

The present study was conducted in the ninth refinery (phase 12) in the SPGC, Bushehr province, Iran, during 2019-2020, using a combined exploratory research method in stages of qualitative, survey validity and reliability of 
researcher-made tools, which are detailed as follows:

Stage 1: Identifying the criteria and indicators of environmental performance in gas refineries using the fuzzy Delphi method (21, 27-29).

Stage 2: Prioritizing and assigning weights to the criteria and indicators using the analytical hierarchy process (AHP) before verifying the results using TOPSIS (Figure $1)$.

As shown in Figure 1, subsequent to reviewing previous works, a list of indicators influencing environmental performance in gas refinaries were identified through interviews with university professors, experts, and ISO 14031 guideline, then, ranked based on the AHP and TOPSIS methods.

The statistical population included all managers and experts working in the gas refinery sector. According to the maximum sample for multi-criteria decision making and using Cochran's formula, the number of interviewees was determined to be 25 experts who had at least 5 years of relevant work experience in the field of HSE and management.
Research information data were collected using a questionnaire appropriate to the EPE indicators including MPIs and OPIs in gas refineries.

Questionnaire data were collected using the coefficient $t$ of these two indicators on an even scale. MPI indicators include 23 indicators that were selected in 4 criteria groups including (a) Implementation of policies and programs, (b) Compliance, (c) Financial performance of the organization, and $(d)$ Social relations. There are also 32 OPI indicators that were selected in 7 main criteria including (a) the amount of raw materials consumed, (b) the amount of energy consumed, (c) support services for organizational activities, $(d)$ equipment and physical facilities, (e) the amount of defective products and incompletely in the year, (f) wastes, and (g) emissions of pollutants in the air and effluents (Figure 2).

The data obtained from the data analysis that express the indicators of EPE, the criteria of environmental performance of the organization were compared (Figure 3). The results of this comparison were extracted in the form of a small range from one (the minimum value) to

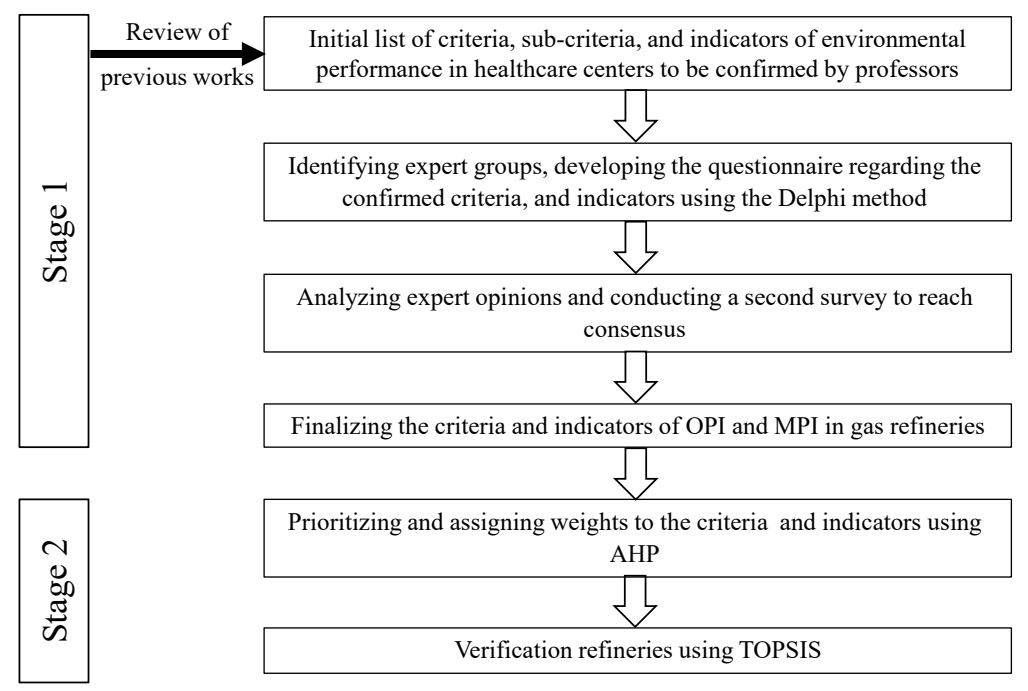

Figure 1. The steps involved in the research process.

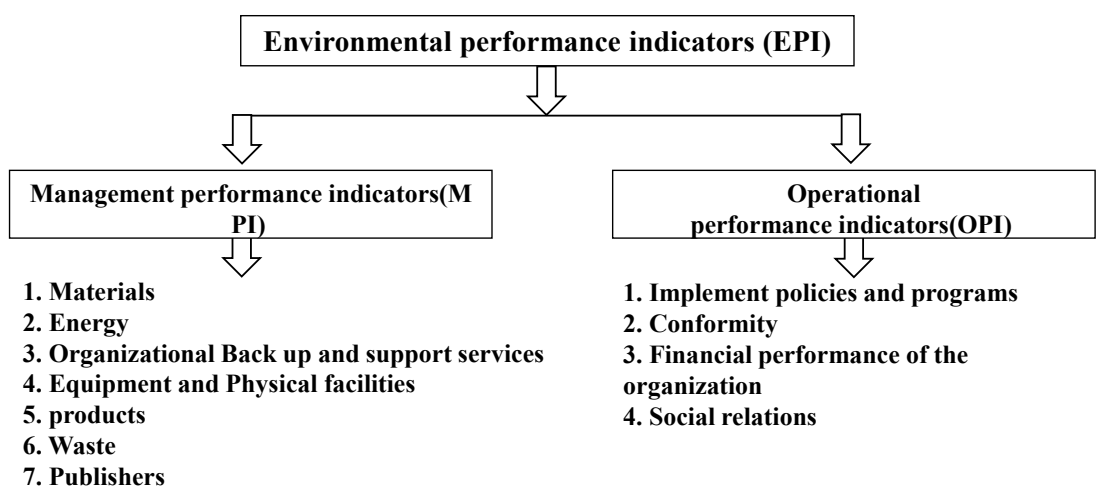

Figure 2. MPI and OPI indicators of gas refinery environmental performance according to ISO 14031 (30). 

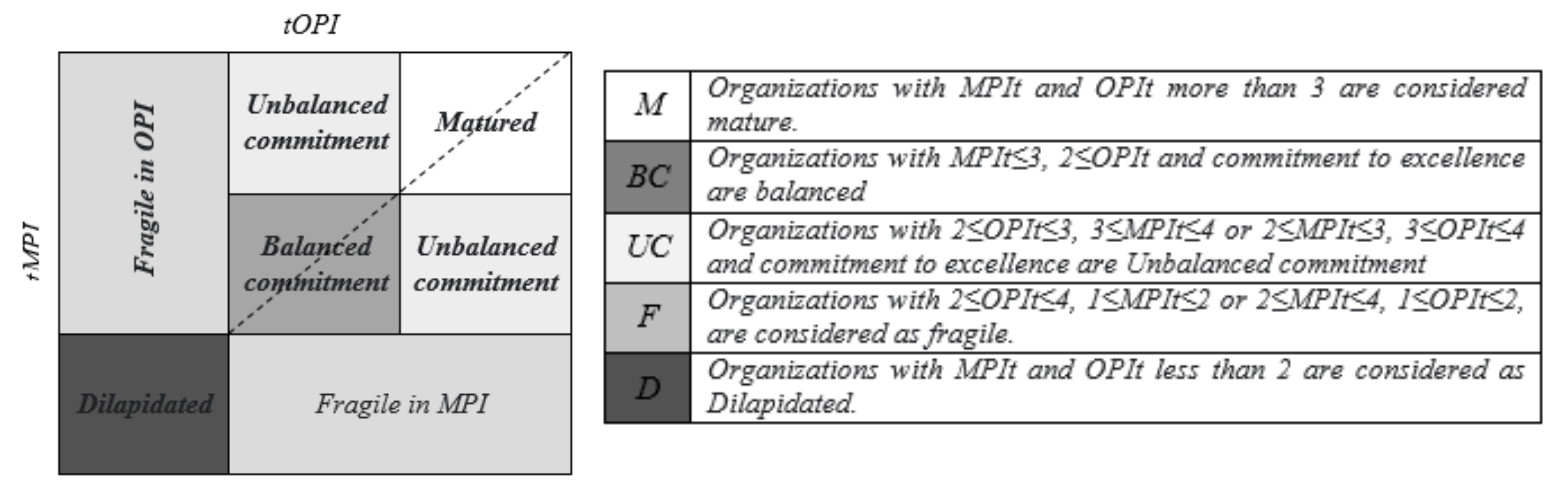

Figure 3. The EPE status of the organization, taking into account the MPI and OPI indicators.

four (the maximum value), which shows the maturity of the organization.

In this research, the AHP was used to weigh the extracted criteria and indicators. Then, the position of the organization in the EPE model was determined, and in the final phase, relative proximity to the ideal positive and negative performances of the four gas refineries in the SPGC was compared using the TOPSIS technique.

The TOPSIS method is based on the concept that the selected option has the least distance with the positive ideal solution and the longest distance with the negative ideal solution (31).

In the present study, the MPI and OPI of the ninth refinery (phase 12) were compared with similar refineries with the same extraction indices of OPIt and MPIt including the first refinery (phase 1), the second refinery (phases 2 and 3) and the third refinery (phases 4 and 5). For this purpose, after weighing the criteria considering the OPI and MPI, the TOPSIS method was applied to rank 4 active refineries of the SPGC and management strategies.

Results

Findings of the questionnaire for zoning MPI and OPI Tables 1 to 9 show the weighting of the all OPIs criteria, separately. Table 10 also summarizes the statistics for weighting of the OPIs criteria. According to this table, the normal weights of the OPI criteria are estimated to be 0.1466958 (materials), 0.2886799 (energy), 0.0208122 (organizational activities support services), 0.0369048

Table 3. Weighting of the OPI 3 criteria (back up and support services)

\begin{tabular}{lcccc}
\hline Indicators & OPI 3-1 & OPI 3-2 & Normal Weight & Geometric Mean \\
\hline OPI 3-1 & 1.00 & 0.14 & 0.13 & 0.38 \\
\hline OPI 3-2 & 7.00 & 1.00 & 0.88 & 2.65 \\
\hline
\end{tabular}

OPI 3-1: The amount of cleaners used by service providers, and OPI 3-2: The amount of recyclable and reusable materials used by service providers.

Table 1. Weighting of the OPI 1 criteria (the amount of consumed raw materials(

\begin{tabular}{lcccccc}
\hline Indicators & OPI 1-1 & OPI 1-5 & OPI 1-3 & OPI 1-4 & OPI 1-5 & Geometric Mean \\
\hline OPI 1-1 & 1.00 & 7.00 & 7.00 & 7.00 & 7.00 & 4.74 \\
\hline OPI 1-2 & 0.14 & 1.00 & 0.20 & 0.14 & 0.33 & 0.587 \\
\hline OPI 1-3 & 0.14 & 5.00 & 1.00 & 5.00 & 0.20 & 0.033 \\
\hline OPI 1-4 & 0.14 & 7.00 & 0.20 & 1.00 & 0.20 & 0.116 \\
\hline OPI 1-5 & 0.14 & 3.00 & 5.00 & 5.00 & 1.00 & 0.065 \\
\hline
\end{tabular}

OPI 1-1: Efficiency (year), OPI 1-2: The amount of recyclable or reusable, OPI 1-3: The amount of consumed water per product, OPI 1-4: The amount of reused water, and OPI 1-5 The amount of reduction in chemical consumption.

Table 2. Weighting of the OPI 2 criteria (the amount of consumed energy)

\begin{tabular}{lccccc}
\hline Indicators & OPI 2-1 & OPI 2-2 & OPI 2-3 & OPI 2-4 & Normal Weight \\
\hline OPI 2-1 & 1.00 & 0.33 & 5.00 & 0.14 & 0.106 \\
\hline OPI 2-2 & 3.00 & 1.00 & 7.00 & 0.14 & 0.200 \\
\hline OPI 2-3 & 0.20 & 0.14 & 1.00 & 0.14 & 0.038 \\
\hline OPI 2-4 & 7.00 & 7.00 & 7.00 & 1.00 & 0.32 \\
\hline
\end{tabular}

OPI 2-1: The amount of steam consumed per product, OPI 2-2: The amount of electricity consumed per product, OPI 2-3: The amount of nitrogen per product, and OPI 2-4: The amount of energy saved. 
Table 4. Weighting of the OPI 4 criteria (equipment and physical facilities)

\begin{tabular}{lccccc}
\hline Indicators & OPI 4-1 & OPI 4-2 & OPI 4-3 & $\begin{array}{c}\text { Normal } \\
\text { Weight }\end{array}$ & $\begin{array}{c}\text { Geometric } \\
\text { Mean }\end{array}$ \\
\hline OPI 4-1 & 1.00 & 8.00 & 5.00 & 0.71 & 3.42 \\
\hline OPI 4-2 & 0.13 & 1.00 & 0.14 & 0.05 & 0.26 \\
\hline OPI 4-3 & 0.20 & 7.00 & 1.00 & 0.23 & 1.12
\end{tabular}

OPI 4-1: Number of emergencies such as explosions or unusual activities such as downtime per year, OPI 4-2: Percentage of green space per industrial area, and OPI 4-3: Preventive maintenance time for equipment per year or product per year

Table 5. Weighting of the OPI 5 criteria (the amount of defective and incomplete products per year)

\begin{tabular}{lccc}
\hline Indicators & OPI 5-1 & Normal Weight & Geometric Mean \\
\hline OPI 5-1 & 1.00 & - & - \\
\hline OPI 5-1: The amount of defective and incomplete products per year
\end{tabular}

Table 6. Weighting of the OPI 6 criteria (waste)

\begin{tabular}{lccccc}
\hline Indicators & OPI 6-1 & OPI 6-2 & OPI 6-3 & $\begin{array}{c}\text { Normal } \\
\text { Weight }\end{array}$ & $\begin{array}{c}\text { Geometric } \\
\text { Mean }\end{array}$ \\
\hline OPI 6-1 & 1.00 & 8.00 & 5.00 & 0.71 & 3.42 \\
\hline OPI 6-2 & 0.13 & 1.00 & 0.14 & 0.05 & 0.26 \\
\hline OPI 6-3 & 0.20 & 7.00 & 1.00 & 0.23 & 1.12 \\
\hline
\end{tabular}

OPI 6-1: ZWI, OPI 6-2: The rate of waste generated into reusable material in a year, and OPI 6-3: The amount of special and hazardous waste removed. (physical equipment and facilities), 0.084132 (products), 0.060128 (waste), and 0.3626473 (emissions). Based on the results, the highest geometric mean among the 7 OPI criteria belongs to the amount of pollutant emissions and energy consumption (3.90 and 3.11, respectively) (Figure 4).

Tables 11 to 14 show the weighting of the four MPIs, separately. Table 15 also presents the weighting of MPIs criteria. According to this table, the normal weight of these indices is as follows: 1- Implementation of policies

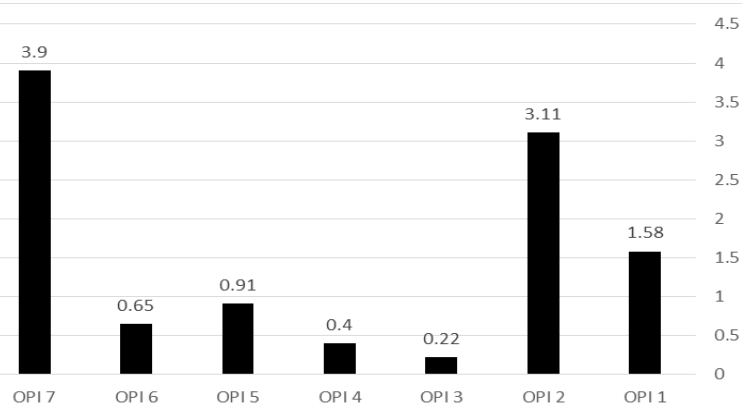

Figure 4. Geometric mean among the $7 \mathrm{OPI}$ criteria in the ninth gas refinery of SPGC.

OPI 1: Materials, OPI 2: Energy, OPI 3: Support services for organizational activities, OPI 4: Equipment and physical facilities, OPI 5: Products, OPI 6: Waste, and OPI 7: Publications.

Table 7. Weighting of the OPI 7 criteria, indices $7-1$ (the amount of pollutants in the air)

\begin{tabular}{lccccccccc}
\hline Indicators & OPI 7-1-1 & OPI 7-1-2 & OPI 7-1-3 & OPI 7-1-4 & OPI 7-1-5 & OPI 7-1-6 & OPI 7-1-7 & Normal Weight & Geometric Mean \\
\hline OPI 7-1-1 & 1.00 & 7.00 & 7.00 & 7.00 & 7.00 & 7.00 & 7.00 & 0.462 & 0.30 \\
\hline OPI 7-1-2 & 0.14 & 1.00 & 0.17 & 0.17 & 0.33 & 0.20 & 0.25 & 0.25 \\
\hline OPI 7-1-3 & 0.14 & 6.00 & 1.00 & 5.00 & 2.00 & 0.20 & 5.00 & 0.119 \\
\hline OPI 7-1-4 & 0.14 & 6.00 & 0.20 & 1.00 & 0.25 & 0.20 & 5.00 & 0.056 \\
\hline OPI 7-1-5 & 0.14 & 3.00 & 0.50 & 4.00 & 1.00 & 0.14 & 5.00 & 0.081 \\
\hline OPI 7-1-6 & 0.14 & 5.00 & 5.00 & 5.00 & 7.00 & 1.00 & 7.00 & 0.230 \\
\hline OPI 7-1-7 & 0.14 & 4.00 & 0.20 & 0.20 & 0.20 & 0.14 & 1.00 & 0.93 \\
\hline
\end{tabular}

OPI 7-1-1: Flaring rate, OPI 7-1-2: $\mathrm{CO}_{2}$, OPI 7-1-3: $\mathrm{SO}_{2}$, OPI 7-1-4: CO, OPI 7-1-5: $\mathrm{NO}_{2}$, OPI 7-1-6: VOC, and OPI 7-1-7: PM.

Table 8. Weighting of the OPI 7 criteria, indices 7-2 (the amount of pollutants in the effluent)

\begin{tabular}{lccccccccc}
\hline Indicators & OPI 7-2-1 & OPI 7-2-2 & OPI 7-2-3 & OPI 7-2-4 & OPI 7-2-5 & OPI 7-2-6 & OPI 7-2-7 & Normal Weight & Geometric Mean \\
\hline OPI 7-2-1 & 1.00 & 6.00 & 7.00 & 7.00 & 7.00 & 6.00 & 7.00 & 0.459 \\
\hline OPI 7-2-2 & 0.17 & 1.00 & 5.00 & 5.00 & 5.00 & 5.00 & 7.00 & 0.232 \\
\hline OPI 7-2-3 & 0.14 & 0.20 & 1.00 & 5.00 & 5.00 & 3.00 & 2.00 & 0.111 \\
\hline OPI 7-2-4 & 0.14 & 0.20 & 0.20 & 1.00 & 2.00 & 0.25 & 2.00 & 0.043 \\
\hline OPI 7-2-5 & 0.14 & 0.20 & 0.20 & 0.50 & 1.00 & 0.25 & 2.00 & 0.035 \\
\hline OPI 7-2-6 & 0.17 & 0.20 & 0.33 & 4.00 & 4.00 & 1.00 & 5.00 & 0.089 \\
\hline OPI 7-2-7 & 0.14 & 0.14 & 0.50 & 0.50 & 0.50 & 0.20 & 1.00 & 0.39 \\
\hline
\end{tabular}

OPI 7-2-1: COD, OPI 7-2-2: BOD, OPI 7-2-3: TSS, OPI 7-2-4: $\mathrm{SO}_{4}$, OPI 7-2-5: PO4, and OPI 7-2-6: OIL, 7-2-7 Detergents 
Table 9. Weighting of the OPI 7 criteria in the emission section

\begin{tabular}{lcccc}
\hline Indicators & Air & Wastewater & Normal Weight & Geometric Mean \\
\hline Air & 1.00 & 2.00 & 0.6666667 & 1.41 \\
\hline Wastewater & 0.50 & 1.00 & 0.3333333 & 0.71 \\
\hline
\end{tabular}

and programs: $0.477925,2$ - Compliance: $0.1233997,3-$ Financial performance of the organization: 0.3410306, and 4- Social relations: 0.0576447. Also, the results of weighting the MPIs show that the highest geometric mean among the four MPIs belongs to the implementation of policies and programs and financial performance of the organization (2.59 and 1.85 , respectively).

\section{Calculation of $t$-coefficient of MPI and OPI}

In this step, according to the evidence found or the available documents and based on the definitions of each index, each indicator was proceeding to score from one to four. It should be noted that the number four is given in the best possible case and the number one is given in the worst case. Accordingly, the following points were obtained by the ninth refinery. The total normal score of the total OPIt was obtained to be 2.3409 and the total normal score of the total MPIt was obtained to be 2.2647 (Tables 16 and 17).

Determining the position of the organization in evaluating environmental performance by considering

Table 10. Weighting of the OPIs criteria

\begin{tabular}{|c|c|c|c|c|c|c|c|c|c|}
\hline Criteria & OPI 1 & OPI 2 & OPI 3 & OPI 4 & OPI 5 & OPI 6 & OPI 7 & Geometric Mean & Normal Weight \\
\hline OPI 1 & 1.00 & 0.20 & 7.00 & 4.00 & 5.00 & 7.00 & 0.13 & 1.58 & 0.147 \\
\hline OPI 2 & 5.00 & 1.00 & 7.00 & 8.00 & 6.00 & 5.00 & 0.33 & 3.11 & 0.289 \\
\hline OPI 3 & 0.14 & 0.14 & 1.00 & 0.33 & 0.20 & 0.17 & 0.13 & 0.22 & 0.021 \\
\hline OPI 4 & 0.25 & 0.13 & 3.00 & 1.00 & 0.25 & 0.20 & 0.33 & 0.40 & 0.037 \\
\hline OPI 5 & 0.20 & 0.17 & 5.00 & 4.00 & 1.00 & 3.00 & 0.25 & 0.91 & 0.084 \\
\hline OPI 6 & 0.14 & 0.20 & 6.00 & 5.00 & 0.33 & 1.00 & 0.17 & 0.65 & 0.060 \\
\hline OPI 7 & 8.00 & 3.00 & 8.00 & 3.00 & 4.00 & 6.00 & 1.00 & 3.90 & 0.363 \\
\hline
\end{tabular}

OPI 1: Materials, OPI 2: Energy, OPI 3: Support services for organizational activities, OPI 4: Equipment and physical facilities, OPI 5: Products, OPI 6: Waste, and OPI 7: Publications.

Table 11. Weighting of the MPI 1 criteria (implementing policies and programs)

\begin{tabular}{lccccccccccc}
\hline Criteria & MPI 1.1 & MPI 1.2 & MPI 1.3 & MPI 1.4 & MPI 1.5 & MPI 1.6 & MPI 1.7 & MPI 1.8 & MPI 1.9 & Geometric Mean & Normal Weight \\
\hline MPI 1.1 & 1.00 & 3.00 & 5.00 & 7.00 & 7.00 & 7.00 & 5.00 & 3.00 & 3.00 & 3.95 \\
\hline MPI 1.2 & 0.33 & 1.00 & 5.00 & 5.00 & 5.00 & 0.33 & 0.33 & 0.20 & 3.00 & 1.12 \\
\hline MPI 1.3 & 0.20 & 0.20 & 1.00 & 2.00 & 3.00 & 0.14 & 0.20 & 0.14 & 2.00 & 0.298 & 0.084 \\
\hline MPI 1.4 & 0.14 & 0.20 & 0.50 & 1.00 & 0.33 & 0.14 & 0.20 & 0.14 & 0.20 & 0.25 \\
\hline MPI 1.5 & 0.14 & 0.20 & 0.33 & 3.00 & 1.00 & 0.20 & 0.20 & 0.14 & 0.14 & 0.31 \\
MPI 1.6 & 0.14 & 3.00 & 7.00 & 7.00 & 5.00 & 1.00 & 3.00 & 2.00 & 7.00 & 2.54 \\
MPI 1.7 & 0.20 & 3.00 & 5.00 & 5.00 & 5.00 & 0.33 & 1.00 & 7.00 & 5.00 & 0.023 \\
\hline MPI 1.8 & 0.33 & 5.00 & 7.00 & 7.00 & 7.00 & 0.50 & 0.14 & 1.00 & 7.00 & 0.192 \\
\hline MPI 9 & 0.33 & 0.33 & 0.50 & 5.00 & 7.00 & 0.14 & 0.20 & 0.14 & 1.00 & 0.160 \\
\hline
\end{tabular}

MPI 1.1: Compliance of the policy with the defined scope of the management system application, MPI 1.2: Influence coefficient definition of environmental objectives in the management sub-departments, MPI 1.3: Per capita of employees whose environmental requirements are seen in their job descriptions, MPI 1.4: Per capita environmental proposals, MPI 1.5: Influence coefficient of environmental proposals, MPI 1.6: Percent of execution environmental proposals, MPI 1.7: Per capita environmental education, MPI 1.8: Environmental education penetration rate, and MPI 1.9: Percent of contractors who have implemented environmental management systems.

Table 12. Weighting of the MPI 2 criteria (compliance)

\begin{tabular}{lccccccc}
\hline Indicators & MPI 2.1 & MPI 2.5 & MPI 2.3 & MPI 2.4 & MPI 2.5 & Normal Weight & Geometric Mean \\
\hline MPI 2.1 & 1.00 & 0.33 & 3.00 & 0.20 & 0.14 & 0.066 \\
\hline MPI 2.2 & 3.00 & 1.00 & 5.00 & 0.33 & 0.20 & 0.134 \\
\hline MPI 2.3 & 0.33 & 0.20 & 1.00 & 0.20 & 0.14 & 0.038 \\
MPI 2.4 & 5.00 & 3.00 & 5.00 & 1.00 & 0.33 & 0.256 \\
MPI 2.5 & 7.00 & 5.00 & 7.00 & 3.00 & 1.00 & 0.504 \\
\hline
\end{tabular}

MPI 2.1: Number of internal and external audits compared to the initial plan, MPI 2.2: Number of rooted environmental accidents, MPI 2.3: Percent of the held maneuvers as the output of the identified risk, MPI 2.4: Percent of remedial measures based on the environmental aspects, and MPI 2.5: Implementation of environmental laws and requirements in the organization. 
Table 13. Weighting of the MPI 3 criteria (organizational financial performance)

\begin{tabular}{|c|c|c|c|c|c|c|}
\hline Indicators & MPI 3.1 & MPI 3.2 & MPI 3.3 & MPI 3.4 & Normal Weight & Geometric Mean \\
\hline MPI 3.1 & 1.00 & 0.14 & 0.20 & 0.25 & 0.29 & 0.050 \\
\hline MPI 3.2 & 7.00 & 1.00 & 3.00 & 5.00 & 3.20 & 0.549 \\
\hline MPI 3.3 & 5.00 & 0.33 & 1.00 & 5.00 & 1.70 & 0.292 \\
\hline MPI 3.4 & 4.00 & 0.20 & 0.20 & 1.00 & 0.63 & 0.108 \\
\hline
\end{tabular}

MPI 3.1: Payment for non-compliance penalties (based on the following method), MPI 3.2: Financial savings through reducing resource use, preventing pollution or returning waste and effluent, MPI 3.3: Environmental budget spent on one year revenue (based on one per thousand sales), and MPI 3.4: Funds provided for research and development on the projects of environmental importance.

Table 14. Weighting of the MPI 4 criteria (social communication)

\begin{tabular}{lcccccc}
\hline Indicators & MPI 4.1 & MPI 4.2 & MPI 4.3 & MPI 4.4 & MPI 4.5 & Normal Weight \\
\hline MPI 4.1 & 1.00 & 3.00 & 5.00 & 3.00 & 0.33 & 0.297 \\
MPI 4.2 & 0.33 & 1.00 & 0.25 & 2.00 & 0.33 & 0.097 \\
MPI 4.3 & 0.20 & 4.00 & 1.00 & 3.00 & 2.00 & 0.237 \\
MPI 4.4 & 0.33 & 0.50 & 0.33 & 1.00 & 0.33 & 0.078 \\
MPI 4.5 & 3.00 & 3.00 & 0.50 & 3.00 & 1.00 & 0.45 \\
\hline
\end{tabular}

MPI 4.1: Environmentally related evaluations of the organization, MPI 4.2: Number of held external meetings, MPI 4.3: Environmental conferences hosted by the organization, MPI 4.4: Number of correspondences and interactions with stakeholders, and MPI 4.5: Number of local cleanup or restoration initiatives, supported or spontaneous.

Table 15. Weighting of MPIs criteria

\begin{tabular}{|c|c|c|c|c|c|c|}
\hline Criteria & MPI 1 & MPI 2 & MPI 3 & MPI 4 & Normal Weight & Geometric Mean \\
\hline MPI 1 & 1.00 & 3.00 & 3.00 & 5.00 & 0.478 & 2.59 \\
\hline MPI 2 & 0.33 & 1.00 & 0.20 & 3.00 & 0.123 & 0.67 \\
\hline MPI 3 & 0.33 & 5.00 & 1.00 & 7.00 & 0.341 & 1.85 \\
\hline MPI 4 & 0.20 & 0.33 & 0.14 & 1.00 & 0.058 & 0.31 \\
\hline
\end{tabular}

MPI 1: Implementation of policies and programs, MPI 2: Compliance, MPI 3: Financial performance of the organization, and MPI 4: Social relations.

the MPI and OPI indices and mapping the path of organizational maturity and excellence

Considering the MPIt of 2.2647 and the OPIt of 2.3409, the organization is balanced in terms of environmental performance. Hence, considering the above-mentioned indices:

Priority 1: In order to comply with the equilibrium line, the organization should upgrade the MPIt from 2.2647 to 2.3409. For this purpose, improvement programs are defined by referring to the points earned and their weight in the MPI indicators.

Comparison of the OPIt and MPIt indices by TOPSIS hierarchical analysis method and determining the rank and position of the organization compared to other similar organizations

The second priority is to raise the OPIt and MPIt indices to a minimum value higher than 2.3409 , which is done by taking into account parameters such as weight, points earned, organizational potentials and requirements, and the path of maturity drawn.

In this section, in order to rank management strategies by integrating the same extracted indices of OPI and MPI, the pairwise comparison matrix of different experts and geometric mean were used. The studied refineries were included the ninth refinery (phase 12), the first refinery (phase 1), the second refinery (phases 2 and 3), and the third refinery (phases 4 and 5), which are named as $A_{1}, A_{2}$, $\mathrm{A}_{3}$, and $\mathrm{A}_{4}$ organizations, respectively.

Tables 18 shows the implementation steps of the TOPSIS method in the ninth refinery with the first, second, and third refineries that had the same extraction indicators of OPIt and MPIt. Due to the relative proximity obtained from the TOPSIS hierarchical analysis method, the options are ranked as $A_{1}>A_{3}>A_{4}>A_{2}$, respectively (Table 19).

\section{Discussion}

ISO 14031 provides a guideline to assess and monitor an organization's ecological performance (32). It explains two aspects of performance pointers: Management performance indicators (MPIs) and operational performance indicators (OPIs) (33).

Unfortunately, the measurement of these indicators remains as one of the greatest difficulties for the organizations and for the certification/competent bodies (12). However, several models have been presented for evaluating environmental performance in Iran $(23,34,35)$. This study, is the first effort of its kind to elicit the weights or the importance of ISO 14031 criteria that apparent by 
Table 16. Scoring of the OPIs criteria and indicators

\begin{tabular}{|c|c|c|c|c|c|}
\hline \multicolumn{3}{|c|}{ Criteria and Indicators of OPI } & Weight & Score & Normal Score \\
\hline \multirow{5}{*}{ Materials } & \multicolumn{2}{|c|}{ 1.1 Efficiency (years) } & 0.086 & 4 & 0.34456885 \\
\hline & \multicolumn{2}{|c|}{ 1.2 Amount of recycled or reusable processed consumables } & 0.005 & 3 & 0.01455464 \\
\hline & \multicolumn{2}{|c|}{ 1.3 The amount of water consumed per product } & 0.017 & 2 & 0.03395799 \\
\hline & \multicolumn{2}{|c|}{ 1.4 Amount of reused water } & 0.01 & 1 & 0.00954003 \\
\hline & \multicolumn{2}{|c|}{ 1.5 Amount of reduction in chemical consumption } & 0.029 & 2 & 0.05836604 \\
\hline \multirow{4}{*}{ Energy } & \multicolumn{2}{|c|}{ 2.1 The amount of steam consumed per product } & 0.031 & 1 & 0.03068883 \\
\hline & \multicolumn{2}{|c|}{ 2.2 The amount of electricity consumed per product } & 0.058 & 1 & 0.05781932 \\
\hline & \multicolumn{2}{|c|}{ 2.3 The amount of nitrogen per product } & 0.011 & 3 & 0.03331366 \\
\hline & \multicolumn{2}{|c|}{ 2.4 The amount of energy saved } & 0.189 & 3 & 0.56720156 \\
\hline \multirow{2}{*}{$\begin{array}{l}\text { Organizational back up } \\
\text { and support services }\end{array}$} & \multicolumn{2}{|c|}{ 3.1 The amount of cleaners used by service providers } & 0.00 & 2 & 0.00520306 \\
\hline & \multicolumn{2}{|c|}{ 3.2 The amount of recyclable and reusable materials used by service providers } & 0.018 & 4 & 0.07284277 \\
\hline \multirow{3}{*}{$\begin{array}{l}\text { Equipment and } \\
\text { physical facilities }\end{array}$} & \multicolumn{2}{|c|}{$\begin{array}{l}\text { 4.1 Number of emergencies such as explosions or unusual activities such as } \\
\text { stopping each year }\end{array}$} & 0.026 & 1 & 0.02629417 \\
\hline & \multicolumn{2}{|c|}{ 4.2 Percentage of green space per industrial area } & 0.002 & 1 & 0.0020096 \\
\hline & \multicolumn{2}{|c|}{ 4.3 Preventive maintenance time for equipment per year or product per year } & 0.009 & 1 & 0.008601 \\
\hline Products & \multicolumn{2}{|c|}{ 5.1 The amount of defective and incomplete products per year } & 0.084 & 1 & 0.08413198 \\
\hline \multirow{3}{*}{ Waste } & \multicolumn{2}{|l|}{$6.1 \mathrm{ZWI}$} & 0.048 & 2 & 0.09593887 \\
\hline & \multicolumn{2}{|c|}{ 6.2 The amount of waste generated per year of reusable material } & 0.008 & 1 & 0.00831504 \\
\hline & \multicolumn{2}{|c|}{ 6.3 The amount of special and hazardous waste removed } & 0.004 & 2 & 0.0076871 \\
\hline \multirow{14}{*}{ Publishers } & \multirow{7}{*}{ Air } & 7.1.1 Flaring rate & 0.112 & 3 & 0.33533099 \\
\hline & & $7.1 .2 \mathrm{CO}_{2}$ & 0.005 & 3 & 0.01599651 \\
\hline & & $7.1 .3 \mathrm{SO}_{2}$ & 0.029 & 3 & 0.08597996 \\
\hline & & 7.1.4 CO & 0.013 & 1 & 0.0134449 \\
\hline & & $7.1 .5 \mathrm{NO}_{2}$ & 0.02 & 2 & 0.03931637 \\
\hline & & 7.1.6 VOC & 0.055 & 2 & 0.11099401 \\
\hline & & 7.1.7 PM & 0.007 & 3 & 0.02218694 \\
\hline & \multirow{7}{*}{ Waste } & 7.2.1 COD & 0.055 & 2 & 0.11088223 \\
\hline & & 7.2.2 BOD & 0.028 & 3 & 0.08407878 \\
\hline & & 7.2.3 TSS & 0.013 & 2 & 0.0269097 \\
\hline & & $7.2 .4 \mathrm{SO}_{4}$ & 0.005 & 1 & 0.00522584 \\
\hline & & $7.2 .5 \mathrm{PO}_{4}$ & 0.004 & 1 & 0.00428694 \\
\hline & & 7.2.6 OIL & 0.011 & 2 & 0.02149376 \\
\hline & & 7.2.7 Detergents & 0.004 & 1 & 0.00370056 \\
\hline
\end{tabular}

the refinery industries.

In this study, the environmental model in the gas refinery was specifically addressed. The comprehensive EPE model introduced in this paper evaluates the environmental performance assessment process based on the OPI and MPI indices.

According to the results obtained from this model, among the OPI indices, the following items had the highest weight: 1- Indices of energy saved, 2- Efficiency (year), 3Flaring rate, 4- VOC, 5- COD, respectively. Also, among the MPIs, 1- Adherence of the policy with the defined scope of application of the management system, 2- Percentage of implementation of environmental proposals, 3- Per capita environmental education, 4- Financial savings due to the reduced use of resources, 5- Preventing pollution or returning waste and effluent, 6- Implementing environmental laws and requirements in the organization, 7- Influencing the definition of environmental goals in the departments under the management had the highest weight, respectively. Therefore, in this model, unlike the models presented so far by the International Organization for Standardization (ISO), the UK Trade Partnerships Programme (UKTP), the European Commission and the Battelle Memorial Institute, the EPE process is introduced comprehensively and comprehensively. This model can be used to evaluate the environmental performance of various types of managerial efforts, organizational operations, environmental conditions and at different organizational and environmental levels as described by Maceno et al (8), Yoonus and Al-Ghamdi (15), and Puig et al (28). 
Table 17. Scoring of the MPIs criteria and indicators

\begin{tabular}{|c|c|c|c|c|}
\hline \multicolumn{2}{|c|}{ Criteria and Indicators of MPI } & \multirow{2}{*}{$\begin{array}{l}\text { Weight } \\
0.14237\end{array}$} & \multirow{2}{*}{$\frac{\text { Score }}{4}$} & \multirow{2}{*}{$\begin{array}{c}\text { Normal Score } \\
0.56947\end{array}$} \\
\hline \multirow{9}{*}{$\begin{array}{l}\text { Implementation of the } \\
\text { policies and programs }\end{array}$} & $\begin{array}{l}\text { 1.1 Policy compliance with the defined scope of application of the management } \\
\text { system }\end{array}$ & & & \\
\hline & $\begin{array}{l}1.2 \text { Influence coefficient of definition of environmental goals in sub-departments of } \\
\text { management }\end{array}$ & 0.04042 & 3 & 0.12127 \\
\hline & $\begin{array}{l}1.3 \text { Per capita employees whose job descriptions meet environmental } \\
\text { requirements }\end{array}$ & 0.01805 & 1 & 0.01805 \\
\hline & 1.4 Per capita environmental proposals & 0.00904 & 2 & 0.01808 \\
\hline & 1.5 Influence coefficient of environmental proposals & 0.01103 & 3 & 0.0331 \\
\hline & 1.6 Percentage (\%) of implementation of environmental proposals & 0.09168 & 4 & 0.36672 \\
\hline & 1.7 Per capita environmental education & 0.0766 & 3 & 0.2298 \\
\hline & 1.8 Impact of environmental education & 0.06765 & 1 & 0.06765 \\
\hline & $\begin{array}{l}\text { 1.9 Percentage (\%) of contractors who have implemented environmental } \\
\text { management systems }\end{array}$ & 0.02108 & 1 & 0.02108 \\
\hline \multirow{5}{*}{ Conformity } & 2.1 Number of internal and external audits compared to the initial plan & 0.00816 & 1 & 0.00816 \\
\hline & 2.2 Number of rooted environmental accidents & 0.01662 & 2 & 0.03324 \\
\hline & 2.3 Percentage (\%) of the held maneuvers as the output of the identified risk & 0.00475 & 3 & 0.01425 \\
\hline & $\begin{array}{l}\text { 2.4 Percentage }(\%) \text { of remedial measures taken based on the significant } \\
\text { environmental aspects }\end{array}$ & 0.03164 & 3 & 0.09493 \\
\hline & 2.5 Implementation of environmental laws and requirements in the organization & 0.06222 & 3 & 0.18667 \\
\hline \multirow{9}{*}{$\begin{array}{l}\text { Financial performance of } \\
\text { the organization }\end{array}$} & 3.1 Payment for penalties for non-compliance & 0.01703 & 3 & 0.05108 \\
\hline & $\begin{array}{l}3.2 \text { Financial savings through reducing resource use, preventing pollution or } \\
\text { returning waste and effluent }\end{array}$ & 0.18747 & 1 & 0.18747 \\
\hline & $\begin{array}{l}\text { 3.3 Environmental budget spent on one year revenue (based on one per thousand } \\
\text { sales) }\end{array}$ & 0.0995 & 1 & 0.0995 \\
\hline & $\begin{array}{l}\text { 3.4 Funds provided for research and development on the projects of environmental } \\
\text { importance }\end{array}$ & 0.03704 & 1 & 0.03704 \\
\hline & 4.1 Environmentally related organizational reviews & 0.01714 & 1 & 0.01714 \\
\hline & 4.2 Number of external meetings held & 0.00559 & 2 & 0.01119 \\
\hline & 4.3 Environmental conferences hosted by the organization & 0.01364 & 2 & 0.02729 \\
\hline & 4.4 Number of correspondences and interactions with stakeholders & 0.00449 & 4 & 0.01796 \\
\hline & 4.5 Number of local cleanup or restoration initiatives, supported or spontaneous & 0.01678 & 2 & 0.03356 \\
\hline
\end{tabular}

Table 18. Implementation steps of the TOPSIS method in the ninth refinery $\left(A_{1}\right)$ with the first $\left(A_{2}\right)$, second $\left(A_{3}\right)$, and third $\left(A_{4}\right)$ refineries

\begin{tabular}{|c|c|c|c|c|c|c|c|c|}
\hline \multirow{2}{*}{ Organization } & \multicolumn{2}{|c|}{ Scores Obtained } & \multicolumn{2}{|c|}{ Calculation of Index Score } & \multicolumn{2}{|c|}{ Index Weights using Shannon Entropy } & \multicolumn{2}{|c|}{ Scaleless Equiponderant Matrix } \\
\hline & MP1 & OPI & MP1 & OPI & MP1 & OPI & MP1 & OPI \\
\hline$A_{1}$ & 2.265 & 2.341 & 0.559 & 0.544 & 0.281 & 0.272 & 0.173 & 0.001 \\
\hline $\mathrm{A}_{2}$ & 1.753 & 2.060 & 0.433 & 0.479 & 0.217 & 0.239 & 0.134 & 0.001 \\
\hline $\mathrm{A}_{3}$ & 2.091 & 1.936 & 0.517 & 0.449 & 0.259 & 0.226 & 0.160 & 0.001 \\
\hline $\mathrm{A}_{4}$ & 1.951 & 2.247 & 0.482 & 0.522 & 0.242 & 0.262 & 0.149 & 0.001 \\
\hline $\mathrm{K}$ & \multicolumn{2}{|c|}{0.721} & & & & & & \\
\hline$E$ & & & & & 0.997 & 0.998 & & \\
\hline $\mathrm{D}$ & & & & & 0.003 & 0.002 & & \\
\hline W & & & & & 0.616 & 0.003 & & \\
\hline MAX & & & & & & & 0.173 & 0.001 \\
\hline MIN & & & & & & & 0.134 & 0.001 \\
\hline
\end{tabular}

In this study, effective variables in evaluating the environmental management and operational performance of the gas refinery included MPIs and OPIs. Among OPI indicators, the most important indices were the amount of energy saved and policy compliance with the defined scope of application of the management system, respectively. From a green management perspective, it can be very important for the refinery (36). 
Table 19. Relative proximity of the options to positive and negative ideals

\begin{tabular}{|c|c|c|c|}
\hline \multicolumn{2}{|c|}{ Positive and Negative Ideals } & \multicolumn{2}{|c|}{ Relative Proximity } \\
\hline$A_{1}+$ & 0.000 & \multirow{2}{*}{$A_{1}$} & \multirow{2}{*}{1} \\
\hline$A_{1}-$ & 0.039 & & \\
\hline $\mathrm{A}_{2}+$ & 0.039 & \multirow{2}{*}{$A_{2}$} & \multirow{2}{*}{0.001} \\
\hline $\mathrm{A}_{2}-$ & 0.000 & & \\
\hline $\mathrm{A}_{3}+$ & 0.013 & \multirow{2}{*}{$\mathrm{A}_{3}$} & \multirow{2}{*}{0.660} \\
\hline $\mathrm{A}_{3}-$ & 0.026 & & \\
\hline $\mathrm{A}_{4}+$ & 0.024 & \multirow{2}{*}{$\mathrm{A}_{4}$} & \multirow{2}{*}{0.387} \\
\hline $\mathrm{A}_{4}-$ & 0.0152 & & \\
\hline
\end{tabular}

Considering the OPIt and MPIt (2.3409 and 2.2647, respectively) is shown the position of the organization in the EPE model. So, the developing organization is balanced. As a result, a comparative model of environmental performance of the country's gas refinery can create a competition in improving the environmental situation. Therefore, this model provides a comparative model that enables the country's gas refinery environment to improve the state of the environment.

The weaknesses of the gas refinery's environmental performance in the OPIs with a standard weight less than 0.01 include: (a) The amount of reused water, (b) Preventive maintenance watch for equipment per year/ product per year, (c) The amount of waste generated per year to reusable material, (d) The removal amount of special and hazardous waste, (e) $\mathrm{SO}_{4}$, (f) The amount of cleaners used by service providers, $(\mathrm{g}) \mathrm{PO}_{4}$, (h) Detergents, and (i) Percentage of green space per industrial area.

The weaknesses of the gas refinery's environmental performance in the MPIs with a standard weight less than 0.01 include (a) Environmental conferences hosted by the organization, (b) Percentage of contractors who have implemented environmental management systems, (c) Per capita environmental proposals, (d) Per capita employees whose job descriptions meet environmental requirements, (e) Number of correspondences and interactions with stakeholders, (f) Environmentally related reviews of the organization, (g) Percentage of held maneuvers as the output of the identified risks, and number of held external meetings, and (h) Number of internal and external audits compared to the initial scheduled.

The strengths of the gas refinery's environmental performance in the OPIs with a standard weight less than 0.01 include (a) The amount of energy saved, (b) Efficiency as years, (c) Flaring rate, (d) VOC, and (e) COD rate.

The strengths of the gas refinery's environmental performance in the MPIs with a standard weight less than 0.01 include:

- Policy compliance with the defined scope of application of the management system

- Percentage of the implementation of environmental proposals

- Per capita environmental education
- Financial savings through reduced resource consumption

- Pollution prevention or recycling of waste and effluent

- Implementation of environmental regulations and requirements in the organization

- Influence coefficient defining environmental goals in management sub-departments

Since the results of this research determined the weight of each of the OPIs and MPIs, and considering that the gas refinery is at a balanced level of development, it can be planned to strengthen the important indicators of the refinery (37). In this case, the collectible collection will be found more competitive than competitors. In addition, refinery planners can increase their weight to more than 3 by planning on important indices; therefore, the refinery can be more competitive and reach the ranks of mature organizations.

The implementation steps of the TOPSIS method showed the rank and position of the organization compared to other similar organizations. Due to the relative proximity obtained from the TOPSIS hierarchical analysis method, the options are ranked as follows:

First Refinery $<$ Third Refinery $<$ Second Refinery $<$ Ninth Refinery

As this research is a pioneer in designing an EPE model in a gas refinery with the proposed method, there is no similar study to compare with, however, the research can be compared with the results of previous studies in some ways.

\section{Conclusion}

According to the results of the present study, petrochemical industries have the potential to cause adverse effects on the environment due to the nature of activities and processes performed and through the production of effluents, emissions, and hazardous wastes.

Given that indices such as the amount of water reuse, the amount of waste generated per year to reusable material, $\mathrm{SO}_{4}$, and $\mathrm{PO}_{4}$ are among the weaknesses of the OPIs, it is suggested that the refinery should take measures in these areas to improve the environmental performance of the gas refinery.

\section{Acknowledgements}

The authors wish to express their gratitude to the SPGC, Bushehr province, IRAN, for supporting this research.

\section{Ethical issues}

The authors hereby certify that all data collected during the study are as stated in the manuscript. This manuscript is the original work of the authors, and no data from the study has been or will be published separated elsewhere. This article was extracted from a $\mathrm{PhD}$ thesis approved by the Environmental Department, Faculty of Natural Resources, Islamic Azad University, Bandar Abbas branch (Approval thesis code: 1144856795126451398162291758). 
It has no ethical issues.

\section{Competing interests}

The authors declare that they have no conflict of interests.

\section{Author's contributions}

The authors contributed and were involved in the problem suggestion, experiments design, data collection, and manuscript approval.

\section{References}

1. Song M, Cen L, Zheng Z, Fisher R, Liang X, Wang Y, et al. How would big data support societal development and environmental sustainability? Insights and practices. Journal of Cleaner Production 2017; 142: 489-500. doi: 10.1016/J.JCLEPRO.2016.10.091.

2. Khan KA, Zaman K, Shoukry AM, Sharkawy A, Gani S, Ahmad J, et al. Natural disasters and economic losses: controlling external migration, energy and environmental resources, water demand, and financial development for global prosperity. Environmental Science and Pollution Research 2019; 26(14): 14287-99. doi: 10.1007/s11356-01904755-5.

3. Ural E, Dadli G. The Effect of problem-based Learning on 7th-grade students' environmental knowledge, attitudes, and reflective thinking skills in environmental education. Journal of Education in Science Environment and Health 2020; 6(3): 177-92. doi: 10.21891/jeseh.705145.

4. Farzadkia M, Ehrampoush MH, Sadeghi S, Kermani M, Ghaneian MT, Ghelmani V, et al. Performance evaluation of wastewater stabilization ponds in Yazd-Iran. Environmental Health Engineering and Management Journal 2014; 1(1): 7-12.

5. Mashfufaha A, Nurkamtob J, Sajidanc W. Development and validity of an environmental knowledge instrument. Development 2020; 13(6): 1-20.

6. Dubey R, Gunasekaran A, Childe SJ, Papadopoulos T, Luo Z, Wamba SF, et al. Can big data and predictive analytics improve social and environmental sustainability? Technological Forecasting and Social Change 2019; 144: 534-45. doi: 10.1016/j.techfore.2017.06.020.

7. Chen J, Xu W, Zuo H, Wu X, Jiaqiang E, Wang T, et al. System development and environmental performance analysis of a solar-driven supercritical water gasification pilot plant for hydrogen production using life cycle assessment approach. Energy Conversion and Management 2019; 184: 60-73. doi: 10.1016/j.enconman.2019.01.041.

8. Maceno MM, Pawlowsky U, Machado KS, Seleme R. Environmental performance evaluation-a proposed analytical tool for an industrial process application. Journal of Cleaner Production 2018; 172: 1452-64. doi: 10.1016/j. jclepro.2017.10.289.

9. Henri JF, Journeault M. Environmental performance indicators: an empirical study of Canadian manufacturing firms. Journal of Environmental Management 2008; 87(1): 165-76. doi: 10.1016/j.jenvman.2007.01.009.

10. Jasch C. Environmental performance evaluation and indicators. Journal of Cleaner Production 2000; 8(1): 79-88. doi: 10.1016/S0959-6526(99)00235-8.
11. Song ML, Fisher R, Wang JL, Cui LB. Environmental performance evaluation with big data: theories and methods. Annals of Operations Research 2018; 270(1-2): 459-72. doi: 10.1007/s10479-016-2158-8.

12. Perotto E, Canziani R, Marchesi R, Butelli P. Environmental performance, indicators and measurement uncertainty in EMS context: a case study. Journal of Cleaner Production 2008; 16(4): 517-30. doi: 10.1016/j.jclepro.2007.01.004.

13. Moktadir MA, Dwivedi A, Rahman A, Chiappetta Jabbour CJ, Paul SK, Sultana R, et al. An investigation of key performance indicators for operational excellence towards sustainability in the leather products industry. Business Strategy and the Environment 2020; 29(8): 3331-51. doi: 10.1002/bse.2575.

14. Mukred M, Yusof ZM, Mokhtar UA, Fauzi F. A framework for electronic records management system adoption in the higher professional education: individual, technological and environmental factors. In: Saeed F, Gazem N, Mohammed F, Busalim A. Recent Trends in Data Science and Soft Computing. Switzerland: Springer; 2019. p.840-9. doi: 10.1007/978-3-319-99007-1_78.

15. Yoonus $\mathrm{H}, \mathrm{Al}$-Ghamdi SG. Environmental performance of building integrated grey water reuse systems based on lifecycle assessment: a systematic and bibliographic analysis. Sci Total Environ 2020; 712: 136535. doi: 10.1016/j. scitotenv.2020.136535.

16. Elmagrhi MH, Ntim CG, Elamer AA, Zhang Q. A study of environmental policies and regulations, governance structures, and environmental performance: the role of female directors. Business Strategy and the Environment 2019; 28(1): 206-20. doi: 10.1002/bse.2250.

17. Umaralievich MS, Jurayevna TM. The role of the internal audit based international internal audit standards in Uzbekistan. Journal of Media \& Management 2020; 2(1): 5.

18. Kazemiyeh F, Sadighi H, Chizari M. Investigation of rural tourism in East Azarbaijan $\mathrm{P}$ rovince of Iran Utilizing SWOT Model and Delphi Technique. Journal of Agricultural Science and Technology 2016; 18(4): 911-23.

19. Vidal R, Sánchez-Pantoja N. Method based on life cycle assessment and TOPSIS to integrate environmental award criteria into green public procurement. Sustainable Cities and Society 2019; 44: 465-74. doi: 10.1016/j.scs.2018.10.011.

20. Sackey S, Kim BS. Environmental and economic performance of asphalt shingle and clay tile roofing sheets using life cycle assessment approach and topsis. Journal of Construction Engineering and Management 2018; 144(11): 04018104. doi: 10.1061/(ASCE)CO.1943-7862.0001564.

21. Sa'idi E, Anvaripour B, Jaderi F, Nabhani N. Fuzzy risk modeling of process operations in the oil and gas refineries. Journal of Loss Prevention in the Process Industries 2014; 30: 63-73. doi: 10.1016/j.jlp.2014.04.002.

22. Kang J, Zhang J, Gao J. Improving performance evaluation of health, safety and environment management system by combining fuzzy cognitive maps and relative degree analysis. Safety Science 2016; 87: 92-100. doi: 10.1016/j. ssci.2016.03.023.

23. Asadzadeh S, Azadeh A, Negahban A, Sotoudeh A. Assessment and improvement of integrated HSE and macro-ergonomics factors by fuzzy cognitive maps: The case of a large gas refinery. Journal of Loss Prevention in the Process Industries 2013; 26(6): 1015-26. doi: 10.1016/j. 
jlp.2013.03.007.

24. Guijarro F. A multicriteria model for the assessment of countries' environmental performance. Int J Environ Res Public Health 2019; 16(16): 2868. doi: 10.3390/ ijerph16162868.

25. Tehran Times. SP complex supplies $40 \%$ of feedstock for gasoline production. [cited 2020 Nov 25] Available from: https://www.tehrantimes.com/news/454710/SP-complexsupplies-40-of-feedstock-for-gasoline-production.

26. National Iranian Oil Company. Iran Oil Ministry Annual Bulletin. 5th ed. National Iranian Oil Company (NIOC); 2019. [In Persian].

27. Shahbod N, Mansouri N, Bayat M, Nouri J, Ghoddousi J. A fuzzy analytic hierarchy process approach to identify and prioritize environmental performance indicators in hospitals. Int J Occup Hyg 2017; 9(2): 66-77 .

28. Puig M, Wooldridge C, Darbra RM. Identification and selection of environmental performance indicators for sustainable port development. Mar Pollut Bull 2014; 81(1): 124-30. doi: 10.1016/j.marpolbul.2014.02.006.

29. Sureeyatanapas P, Tawwan K. Environmental performance assessment using the evidential reasoning approach: The case of logistics service providers. MATEC Web of Conferences 2018; 192: 01021. doi: 10.1051/matecconf/201819201021.

30. ISO. Environmental management - Environmental performance evaluation - Guidelines. [cited 2020 Nov 12] Available from: https://www.iso.org/standard/52297.html.

31. Ighravwe DE, Babatunde DE. Evaluation of landfill gas plant siting problem: a multi-criteria approach. Environmental Health Engineering and Management Journal 2019; 6(1): 1-10. doi: 0.15171/EHEM.2019.01.
32. Ferreira LM, Silva C, Azevedo SG. An environmental balanced scorecard for supply chain performance measurement (Env_BSC_4_SCPM). Benchmarking An International Journal 2016; 23(6): 1-27. doi: 10.1108/BIJ08-2013-0087.

33. 33 Tam C, Tam VW, Zeng SX. Environmental performance evaluation (EPE) for construction. Building Research \& Information 2002; 30(5): 349-61. doi: 10.1080/09613210210150964.

34. 34 Malmasi S, Jozi SA, Monavari SM, Jafarian Moghadam E. Environmental impacts of PET- PTA petrochemical industries (case study: mahshahr economic special zone) Journal of Human and Environment 2011; 8(4): 73-81. [In Persian].

35. Hashemi H, Amin MM, Ebrahimi A, Rezai R, Safari M. Evaluation of health, environmental, economic and technical aspects of disinfection of WWTP effluent in the north of Isfahan with UV instead of chlorine. Scientific Journal of Kurdistan University of Medical Sciences 2011; 16(4): 50-9. [In Persian].

36. Mikulčić H, Baleta J, Wang X, Duić N, Dewil R. Green development challenges within the environmental management framework. J Environ Manage 2021; 277: 111477. doi: 10.1016/j.jenvman.2020.111477.

37. Hashemi F, Hashemi H, Shahbazi M, Dehghani M, Hoseini M, Shafeie A. Reclamation of real oil refinery effluent as makeup water in cooling towers using ultrafiltration, ion exchange and multioxidant disinfectant. Water Resources and Industry 2020; 23: 100123. doi: 10.1016/j. wri.2019.100123. 